\title{
Blood Levels of Oxidant/Antioxidant Parameters in Rats Infected with Toxoplasma gondii
}

\author{
Somayeh Bahrami, ${ }^{1}$ Ali Shahriari, ${ }^{2}$ Mehdi Tavalla, ${ }^{3}$ \\ Somayeh Azadmanesh, ${ }^{1}$ and Hossein Hamidinejat ${ }^{1}$ \\ ${ }^{1}$ Department of Parasitology, Faculty of Veterinary Medicine, Shahid Chamran University of Ahvaz, Ahvaz, Iran \\ ${ }^{2}$ Department of Biochemistry, Faculty of Veterinary Medicine, Shahid Chamran University of Ahvaz, Ahvaz, Iran \\ ${ }^{3}$ Department of Medical Parasitology, Faculty of Medicine, Jundishapur University of Medical Sciences, Ahvaz, Iran \\ Correspondence should be addressed to Somayeh Bahrami; s.bahrami@scu.ac.ir
}

Received 6 April 2016; Revised 25 July 2016; Accepted 6 September 2016

Academic Editor: Claudio Cabello-Verrugio

Copyright (C) 2016 Somayeh Bahrami et al. This is an open access article distributed under the Creative Commons Attribution License, which permits unrestricted use, distribution, and reproduction in any medium, provided the original work is properly cited.

\begin{abstract}
Toxoplasmosis is a common parasitic infection in the world. Since increased free radicals and oxidative stress are reported in many parasitic diseases the purpose of the present study was to evaluate the oxidative stress in acute and chronic toxoplasmosis. RH strains of Toxoplasma tachyzoites were used in the present study. Twenty-five female rats were infected with the parasite while 25 other rats were as the control group that received normal saline. Zero-, 5-, 7-, 10-, and 45-day postinfection (DPI) blood samples were taken. Some parameters related to oxidant and antioxidants such as antioxidant enzymes, malondialdehyde, and total antioxidant capacity were measured. On day 7 after infection, GPX activity and GSH level were significantly increased and in the mentioned day the amount of total antioxidant capacity was significantly reduced. In other cases, there were no significant differences between the groups in different days. Overall, based on the results it seems that, on day 7 after infection, in infected rats responses to oxidative stress were triggered and led to decrease of total antioxidant capacity. Furthermore, glutathione was increased to cope with stress. It seems that probably antioxidant defense system entered the infection to the chronic phase and changed the parasites stage.
\end{abstract}

\section{Introduction}

Toxoplasma gondii is an obligate intracellular protozoan parasite responsible for toxoplasmosis, a disease that affects many mammals including man $[1,2]$. Infection of an immunocompetent individual is usually asymptomatic; however, infection of immunocompromised individuals or congenital infection of a fetus can lead to debilitating or life-threatening illness. Infection generally occurs through either ingestion of oocysts shed in the faeces of a cat, which is the definitive host, or ingestion of viable tissue-cysts in undercooked meat. When primary infection occurs during pregnancy, congenital transmission could occur. Initial infection and acute disease are characterized by the presence of fast-replicating tachyzoites. Around 10-14 days after infection, tachyzoites differentiate into bradyzoites that replicate more slowly and form cysts in tissues throughout the body. Tissue cysts are long-lived and not associated with disease. However, in people with immunodeficiency, such as AIDS or malignancies, rupture of tissue cysts and the transformation of bradyzoites to tachyzoites result in disease reactivation. Congenitally infected individuals are also at risk of repeated disease reactivation, most notably in their brain and eyes, although the reason(s) for this has not been established. Recent investigations indicate that parasitic infections with high tolerance of the host are the result of defense mechanisms which include enhanced generation of reactive oxygen species (ROS) $[3,4]$. Cells and biological fluids from an antioxidant defense system aid at suppression of ROS generation and prevention of ROS reactions with cellular components. A balance between oxidants and antioxidant is known to exist under physiological conditions. However, even small changes in oxidant or/and antioxidant levels may disturb its balance and leads to oxidative stress. This situation becomes dangerous when the antioxidant system is unable to prevent oxidative reactions triggered by ROS and directed oxidative modification of 
lipids, proteins, and DNA [5-7]. Free radicals are produced continuously by normal metabolic processes, but their rate of production increases during certain parasitic infections.

Stage conversion between tachyzoite and bradyzoite forms of Toxoplasma is associated with morphological and molecular biological changes, including stage-specific antigen expression and alterations to metabolism [8]. Different studies confirmed that alkaline medium, heat shock protein, and acid conditions can induce stage conversion in vitro. These methods appear to rely on stressing the parasites. Having these facts in mind, the present study was designed to compare the antioxidant profile of rats during acute and chronic toxoplasmosis and investigate probable role of oxidative stress in Toxoplasma gondii tachyzoite-bradyzoite interconversion.

\section{Materials and Methods}

2.1. Parasite. The virulent RH strain of T. gondii was obtained from Jundishapur University of Medical Sciences, Ahvaz, Iran. Tachyzoites of this strain were collected by serial intraperitoneal passages in BALB/c mice. Parasites $\left(1 \times 10^{5}\right)$ were inoculated in the mice, and after 72 hours, tachyzoites were provided by repeated flushing of the peritoneal cavity by phosphate buffered saline (PBS). Tachyzoites were then harvested and centrifuged at $200 \times \mathrm{g}$ for $5 \mathrm{~min}$ at room temperature to remove peritoneal cells and cellular debris. The supernatants were collected and centrifuged at $800 \times \mathrm{g}$ for $10 \mathrm{~min}$. The pellets, enriched with parasite tachyzoites, were recovered with PBS and used in the experiments [9].

2.2. In Vivo Study. Fifty female Wistar rats, 8 to 10 weeks old, approximately 250-280 g, were purchased from laboratory animal breeding council (Jundishapur University of Medical Science, Ahvaz, Iran). They were housed in a room under controlled temperature $\left(24 \pm 2^{\circ} \mathrm{C}\right)$, lighting $(12 \mathrm{~h}$ light/dark cycle), and relative humidity $40-70 \%$ conditions. During experiment, all rats had free access to water and standard rat chow. After 1 week acclimation, firstly modified agglutination test was used to ensure rats were not already infected with Toxoplasma, and then they were divided randomly into two equal groups: The infected and control groups were each inoculated intraperitoneally with $1 \times 10^{7}$ organisms [10] and normal saline, respectively. On days $0,5,7,10$, and 45 after infection, five rats from each group were euthanized in a glass desiccator jar for open-drop anesthesia with chloroform following standard animal ethics guidelines of Iran. Blood samples were obtained by cardiac puncture into sterile vacuum tubes with and without anticoagulant (EDTA). Serum was separated by centrifuge and stored at $-20^{\circ} \mathrm{C}$ until use. During the present study, the animals were handled according to the recommendation of the Ethics Committee, Shahid Chamran University of Ahvaz, Ahvaz, Iran (Ethical Approval number 29/6/94, 30 Sept. 2014). Acute and chronic toxoplasmosis of was confirmed by PCR and modified agglutination test (MAT), respectively.
2.3. DNA Extraction and Polymerase Chain Reaction (PCR) Amplification. Induction of acute toxoplasmosis was confirmed with PCR in infected rats on days 5, 7, and 10 after infection. DNA was extracted from whole blood using a genomic DNA purification kit (CinnaGen, Iran). For detection of T. gondii DNA, primers targeting the G529 gene were selected from the literature [11]. PCR reactions included a negative control, consisting of the reaction mix and $2 \mu \mathrm{L}$ of DNase/RNase-free water and a positive control that consisted of a DNA sample from the tachyzoites of T. gondii. All PCR were performed in a $25 \mu \mathrm{L}$ reaction containing $12.5 \mu \mathrm{L}$ Taq DNA polymerase master mix Red (Amplicon, Denmark), $1 \mu \mathrm{M}$ primers, and $50 \mathrm{ng}$ DNA templates. PCR cycling included an initial denaturation at $94^{\circ} \mathrm{C}$ for $4 \mathrm{~min}$, followed by 30 cycles of denaturation at $94^{\circ} \mathrm{C}$ for $50 \mathrm{~s}$, annealing at $57^{\circ} \mathrm{C}$ for $50 \mathrm{~s}$, and extension at $72^{\circ} \mathrm{C}$ for $60 \mathrm{~s}$. This was followed by a final extension at $72^{\circ} \mathrm{C}$ for $5 \mathrm{~min}$. PCR products were electrophoresed in 1.5\% agarose (SinaClon Bioscience, Iran) in Tris-acetic acid-EDTA (TAE) buffer, stained with Green Safe stain (SinaClon Bioscience, Iran), and visualized under ultraviolet light. Positive samples showed a band of approximately $400 \mathrm{bp}$.

2.4. Modified Agglutination Test. To ensure that chronic toxoplasmosis occurred in rats on day 45 after infection, MAT was used as described by Desmonts and Remington and Dubey and Desmonts $[12,13]$. The sera were diluted twofold (1:20 to $1: 320)$ with phosphate buffered saline containing $0.2 \mathrm{M} 2$-mercaptoethanol and $50 \mu \mathrm{L}$ of each dilution was put in a well of $96 \mathrm{U}$-bottom ELISA plates. Thereafter, $50 \mu \mathrm{L}$ of the whole formalin-preserved T. gondii tachyzoites was added to each serum dilution. The wells were then mixed thoroughly by pipetting up and down several times, covered, and then incubated at $37^{\circ} \mathrm{C}$ overnight. The test was considered positive when a layer of agglutinated parasites was formed in wells at dilutions of 1:20 or higher. Positive and negative controls were included in each test.

2.5. Oxidant/Antioxidant Assessment. The determination of the SOD activity was based on the generation of superoxide radicals produced by xanthine and xanthine oxidase, which react with 2-(4-iodophenyl)-3-(4-nitrophenol)5-phenyltetrazolium chloride to form a red formazon dye. Briefly, $300 \mu \mathrm{L}$ of mixed substrate was added to $200 \mu \mathrm{L}$ of diluted hemolysates. The samples were mixed well and $75 \mu \mathrm{L}$ xanthine oxidase was added to reactions. The absorbance was measured at $505 \mathrm{~nm}$ and the SOD activity was then calculated according to the manufacturer's instruction (Ransod ${ }^{\circledR}$ Randox Lab, Antrim, UK) and expressed as U/mL.

Glutathione peroxidase activity was determined based on the fact that GPX catalyzed the oxidation of glutathione by cumene hydroperoxide. In presence of the glutathione reductase and nicotinamide adenine dinucleotide phosphate (NADPH), the oxidized glutathione was immediately converted to the reduced form with concomitant oxidation of $\mathrm{NADPH}$ to $\mathrm{NADP}^{+}$. To evaluate GPX activity in hemolysates $10 \mu \mathrm{L}$ of samples was mixed with $500 \mu \mathrm{L}$ reagent $\mathrm{R} 1$ and $20 \mu \mathrm{L}$ cumene $\mathrm{R} 2$. The absorbance was measured at $340 \mathrm{~nm}$ 
and the GPX activity was then calculated according to the manufacturer's instruction (Ranse ${ }^{\circledR}{ }^{\circledR}$ Randox Lab, Antrim, $\mathrm{UK})$. The enzymes activities were expressed as $\mathrm{U} / \mathrm{mL}$.

The procedure to estimate the reduced glutathione (GSH) level followed the method described by Ellman [14]. In this method thiols react with Ellman's reagent (5,5' -dithiobis-(2nitrobenzoic acid) or DTNB), cleaving the disulfide bond to give 2-nitro-5-thiobenzoate $\left(\mathrm{TNB}^{-}\right)$, which ionizes to the $\mathrm{TNB}^{2-}$ dianion in water at neutral and alkaline $\mathrm{pH}$.

To evaluate GSH level in samples, $15 \mu \mathrm{L}$ of hemolysates was mixed with $260 \mu \mathrm{L}$ assay buffer $(0.1 \mathrm{M}$ sodium phosphate and $1 \mathrm{mM}$ EDTA, pH: 8) and $5 \mu \mathrm{L}$ Ellman reagents. Samples were incubated for $15 \mathrm{~min}$ at room temperature and the $\mathrm{TNB}^{2-}$ formation was quantified in a spectrophotometer by measuring the absorbance of visible light at $412 \mathrm{~nm}$. Absorbance values were compared with a standard curve generated from standard curve from known GSH.

Catalase activity was determined spectrophotometrically by the method of Koroliuk et al. [15]. Briefly, $10 \mu \mathrm{L}$ of sample was incubated with $100 \mu \mathrm{mol} / \mathrm{mL}$ of $\mathrm{H}_{2} \mathrm{O}_{2}$ in $0.05 \mathrm{mmol} / \mathrm{L}$ Tris- $\mathrm{HCl}$ buffer $\mathrm{pH}=7$ for $10 \mathrm{~min}$. The reaction was terminated by rapidly adding $50 \mu \mathrm{L}$ of $4 \%$ ammonium molybdate. Yellow complex of ammonium molybdate and $\mathrm{H}_{2} \mathrm{O}_{2}$ was measured at $410 \mathrm{~nm}$. One unit of catalase activity was defined as the amount of enzyme required to decompose $1 \mu \mathrm{mol} \mathrm{H}_{2} \mathrm{O}_{2}$ per min.

Total antioxidant capacity of serum was measured according to the method of Benzie and Strain [16]. Briefly, a working solution of FRAP (ferric reducing antioxidant power) was provided by mixing buffer acetate with TPTZ solution in $\mathrm{HCl}$. After that $\mathrm{FeCl}_{3}$ was added and mixed. $8 \mu \mathrm{L}$ of serum and $240 \mu \mathrm{L}$ of mentioned working solution were mixed and incubated for $10 \mathrm{~min}$ at room temperature. The optical density of samples was measured at $532 \mathrm{~nm}$. Total antioxidant capacity was expressed as $\mathrm{mmol} / \mathrm{L}$.

Malondialdehyde levels in samples were measured using the thiobarbituric acid reaction method of Placer et al. [17]. Quantification of the thiobarbituric acid reactive substances was determined at $532 \mathrm{~nm}$ by comparing the absorption to the standard curve of MDA equivalents generated by acid-catalyzed hydrolysis of 1,1,3,3-tetramethoxypropane. To measure MDA level, a working solution containing 15\% trichloroacetic acid, $0.375 \%$ thiobarbituric acid, and $0.25 \mathrm{~N}$ hydrochloric acid was prepared. For each sample, $250 \mu \mathrm{L}$ serum and $500 \mu \mathrm{L}$ working solution were mixed and placed in boiling water for $10 \mathrm{~min}$. After cooling the samples were centrifuged at $3000 \mathrm{rpm}$ for $10 \mathrm{~min}$. Finally $200 \mu \mathrm{L}$ of each supernatant was transferred to microplates and the optical density of samples was measured at $535 \mathrm{~nm}$. The values of MDA were expressed as $\mu \mathrm{mol} / \mathrm{L}$.

2.6. Statistical Analysis. The mean value and standard error were calculated for each group of measurements. The Kolmogorov-Smirnov test was used to test the normal distribution of the data before statistical analysis was performed. Statistical analyses were conducted with the general linear model procedure of SAS for Windows version 9.1 (SAS, 1998) to determine if variables differed between groups.
Whenever significant differences were found, mean values were compared by the Tukey test. A probability value of less than 0.05 was considered significant.

\section{Results}

After induction of experimental toxoplasmosis, acute toxoplasmosis was confirmed by PCR. In all the samples obtained 5 and 7 days after infection, DNA of Toxoplasma was detected in blood. Ten days after infection except for the two samples others were positive. Although in two samples DNA was not detected they were serologically positive. The accuracy of experimental chronic toxoplasmosis induction (samples obtained 45 days after infection) was serologically checked out. In all the samples complete carpet of agglutinated organisms was seen and considered as positive.

The antioxidant enzymes activities, total antioxidant capacity, and MDA level in blood of experimentally infected rats were compared to those of noninfected.

Changes of SOD activity in different days in infected ( $p=$ $0.91)$ and uninfected group $(p=0.62)$ were not significant. Also after comparing SOD activity in infected and uninfected groups on the days $0(p=0.81), 5(p=0.36), 7(p=0.75)$, $10(p=0.35)$, and $45(p=0.80)$ after infection, significant changes were not found (Table 1).

According to our data, level of GSH in noninfected rats in different days was not significantly changed while, in infected rats on the 7 th day after infection, GSH was significantly increased comparing to 5 th $(p=0.002), 10$ th $(p=0.001)$, and 45 th $(p=0.001)$ day after infection. After comparing GSH level in infected and uninfected rats on the days $0(p=0.57)$, $5(p=0.22)$, and $45(p=0.55)$ after infection, significant changes were not found whereas on day 7 ( $p=0.019) \mathrm{GSH}$ level was substantially increased (Table 2$)$.

Changes of GPX activity on days $5(p=0.03)$ and $7(p=$ 0.04 ) after infection were significant in infected group. Also significant differences were detected in GPX activity between the infected rats and the controls on days $5(p=0.03)$ and 7 $(p=0.02)$ after infection (Table 3$)$.

As shown in Table 4 the values for the activity of catalase in infected and uninfected rats were constant throughout the experiment. Also no significant differences were detected in catalase activity between the infected rats and the controls on days $0(p=0.72), 5(p=0.57), 7(p=0.51), 10(p=0.53)$, and $45(p=0.75)$ after infection.

The control value for the total antioxidant capacity in uninfected rats was constant throughout all stages of experiment whilst a statically significant decrease in the total antioxidant capacity was noticed on day 7 after infection in infected ones $(p=0.004)$. Significant difference was detected in total antioxidant capacity between the infected rats and the control ones on day 7 after infection $(p=0.02)$ (Table 5).

Changes of MDA level in different days in infected ( $p=$ $0.57)$ and uninfected rats $(p=0.21)$ were not significant. Also after comparing MDA level in infected and uninfected groups on days $0(p=0.53), 5(p=0.49), 7(p=0.12), 10(p=0.15)$, and $45(p=0.28)$ after infection, significant changes were not found (Table 6). 
TABLE 1: Mean \pm standard error of SOD activity $(\mathrm{U} / \mathrm{mL})$ in noninfected and $T$. gondii infected rats.

\begin{tabular}{lccccc}
\hline & & \multicolumn{3}{c}{ Days after infection } & \\
& 0 & 5 & 7 & 10 & 45 \\
\hline Infected & $98.2 \pm 10.3^{\mathrm{Aa}}$ & $103.1 \pm 9.3^{\mathrm{Aa}}$ & $114.2 \pm 13.9^{\mathrm{Aa}}$ & $114.3 \pm 15.3^{\mathrm{Aa}}$ & $104.6 \pm 17.8^{\mathrm{Aa}}$ \\
Noninfected & $94.6 \pm 8.7^{\mathrm{Aa}}$ & $85.1 \pm 16.3^{\mathrm{Aa}}$ & $107.2 \pm 16.2^{\mathrm{Aa}}$ & $91.1 \pm 18.05^{\mathrm{Aa}}$ & $110 \pm 10.8^{\mathrm{Aa}}$ \\
\hline
\end{tabular}

Values in columns and rows with different uppercase and lowercase superscripts are significantly different $(p<0.05)$.

TABLE 2: Mean \pm standard error of GSH level $(\mu \mathrm{mol} / \mathrm{mL})$ in noninfected and T. gondii infected rats.

\begin{tabular}{|c|c|c|c|c|c|}
\hline & \multicolumn{5}{|c|}{ Days after infection } \\
\hline & 0 & 5 & 7 & 10 & 45 \\
\hline Infected & $72.6 \pm 5.3^{\mathrm{Aa}}$ & $78.6 \pm 7.7^{\mathrm{Aa}}$ & $174.7 \pm 16.4^{\mathrm{Bb}}$ & $52.1 \pm 6.3^{\mathrm{Aa}}$ & $75.4 \pm 18.3^{\mathrm{Aa}}$ \\
\hline Noninfected & $70.3 \pm 5.4^{\mathrm{Aa}}$ & $66.6 \pm 4.9^{\mathrm{Aa}}$ & $98.4 \pm 14.9^{\mathrm{Bb}}$ & $106.2 \pm 20.4^{\mathrm{Aa}}$ & $90.4 \pm 14.4^{\mathrm{Aa}}$ \\
\hline
\end{tabular}

Values in columns and rows with different uppercase and lowercase superscripts are significantly different $(p<0.05)$.

TABLE 3: Mean \pm standard error of GPX activity $(\mathrm{U} / \mathrm{mL})$ in noninfected and T. gondii infected rats.

\begin{tabular}{lccccc}
\hline & & \multicolumn{3}{c}{ Days after infection } & \\
& 0 & 5 & 7 & 10 & 45 \\
\hline Infected & $114.4 \pm 11.6^{\mathrm{Aa}}$ & $313.5 \pm 43.53^{\mathrm{Bb}}$ & $296.47 \pm 42.1^{\mathrm{Bb}}$ & $128.1 \pm 30.3^{\mathrm{Aa}}$ & $118.6 \pm 28.7^{\mathrm{Aa}}$ \\
Noninfected & $117.3 \pm 10.9^{\mathrm{Aa}}$ & $114.6 \pm 14.4^{\mathrm{Aa}}$ & $107.4 \pm 19.4^{\mathrm{Aa}}$ & $121.6 \pm 23.4^{\mathrm{Aa}}$ & $107.1 \pm 18.1^{\mathrm{Aa}}$ \\
\hline
\end{tabular}

Values in columns and rows with different uppercase and lowercase superscripts are significantly different $(p<0.05)$.

TABLE 4: Mean \pm standard error of catalase activity $(\mathrm{U} / \mathrm{mL})$ in noninfected and T. gondii infected rats.

\begin{tabular}{lccccc}
\hline & & \multicolumn{3}{c}{ Days after infection } & \\
& 0 & 5 & 7 & 10 & 45 \\
\hline Infected & $513.5 \pm 82.3^{\mathrm{Aa}}$ & $466.8 \pm 88.1^{\mathrm{Aa}}$ & $515.8 \pm 63.2^{\mathrm{Aa}}$ & $551.5 \pm 32.4^{\mathrm{Aa}}$ & $408.5 \pm 78.8^{\mathrm{Aa}}$ \\
Noninfected & $532.5 \pm 78.2^{\mathrm{Aa}}$ & $528.5 \pm 75.6^{\mathrm{Aa}}$ & $427.5 \pm 105.3^{\mathrm{Aa}}$ & $471.2 \pm 88.7^{\mathrm{Aa}}$ & $449.7 \pm 95.3^{\mathrm{Aa}}$ \\
\hline
\end{tabular}

Values in columns and rows with different uppercase and lowercase superscripts are significantly different $(p<0.05)$.

TABLE 5: Mean \pm standard error of total antioxidant capacity $(\mathrm{mmol} / \mathrm{L})$ in noninfected and T. gondii infected rats.

\begin{tabular}{|c|c|c|c|c|c|}
\hline & \multicolumn{5}{|c|}{ Days after infection } \\
\hline & 0 & 5 & 7 & 10 & 45 \\
\hline Infected & $987.2 \pm 218.3^{\mathrm{Aa}}$ & $1016 \pm 138.5^{\mathrm{Aa}}$ & $366.3 \pm 53.6^{\mathrm{Bb}}$ & $1064.0 \pm 70.7^{\mathrm{Aa}}$ & $1124.0 \pm 105.3^{\mathrm{Aa}}$ \\
\hline Noninfected & $874.1 \pm 128.3^{\mathrm{Aa}}$ & $869.6 \pm 125.5^{\mathrm{Aa}}$ & $895.6 \pm 314.8^{\mathrm{Aa}}$ & $816.1 \pm 169.9^{\mathrm{Aa}}$ & $961.72 \pm 172.3^{\mathrm{Aa}}$ \\
\hline
\end{tabular}

Values in columns and rows with different uppercase and lowercase superscripts are significantly different $(p<0.05)$.

TABLE 6: Mean \pm standard error of MDA $(\mu \mathrm{mol} / \mathrm{L})$ in noninfected and T. gondii infected rats.

\begin{tabular}{lccccc}
\hline & & \multicolumn{3}{c}{ Days after infection } & \\
& 0 & 5 & 7 & 10 & 45 \\
\hline Infected & $20.6 \pm 3.2^{\mathrm{Aa}}$ & $22.16 \pm 5.4^{\mathrm{Aa}}$ & $13.56 \pm 2.9^{\mathrm{Aa}}$ & $13.07 \pm 1.2^{\mathrm{Aa}}$ & $15.5 \pm 2.8^{\mathrm{Aa}}$ \\
Noninfected & $19.6 \pm 3.2^{\mathrm{Aa}}$ & $18.2 \pm 2.7^{\mathrm{Aa}}$ & $25.6 \pm 6.01^{\mathrm{Aa}}$ & $18.5 \pm 3.2^{\mathrm{Aa}}$ & $21.7 \pm 4.1^{\mathrm{Aa}}$ \\
\hline
\end{tabular}

Values in columns and rows with different uppercase and lowercase superscripts are significantly different $(p<0.05)$.

\section{Discussion}

A critical aspect of host defense to Toxoplasma gondii is the activation of parasiticidal mechanisms in host leukocytes. Mononuclear phagocytes, particularly macrophages that have been activated by lymphokines, are the principal defense against intracellular pathogens such as T. gondii and respiratory burst (rapid release of reactive oxygen species) plays an important role against T. gondii [18]. One of the mechanisms that protect the host cells against excess free radicals is the enzymatic antioxidant defense which includes SOD, catalase, peroxiredoxins, flavor hemoglobins, and glutathione S-transferase/GPX coupled to glutathione reductase. SOD is a key enzyme that appears to act as the first line defense against ROS but in the present study its activity was constant throughout all stages of experiment in infected rats. 
Glutathione peroxidase and catalase are the two main enzymes involved in $\mathrm{H}_{2} \mathrm{O}_{2}$ detoxification [19]. Hydrogen peroxide $\left(\mathrm{H}_{2} \mathrm{O}_{2}\right)$ is one of the main reactive oxygen species (ROS) leading to oxidative stress [20]. $\mathrm{H}_{2} \mathrm{O}_{2}$ is continuously generated by several enzymes (including superoxide dismutase, glucose oxidase, and monoamine oxidase) and must be degraded to prevent oxidative damage. The cytotoxic effect of $\mathrm{H}_{2} \mathrm{O}_{2}$ is thought to be caused by hydroxyl radicals generated from iron-catalyzed reactions, causing subsequent damage to DNA, proteins, and membrane lipids [21]. According to our results significant changes of catalase activity were not found during the experiment in infected rats while GSH level and GPX activity were substantially increased on the 7th day after infection. This is despite the fact that GSH elevation may be due to stimulation of antioxidant defense system against infection. GPX are a family of seleniumcontaining antioxidant enzymes that catalyze the reduction of hydrogen peroxide in the presence of reduced glutathione [22]. Glutathione exists in both reduced (GSH) and oxidized (GSSG) states. In the reduced state, the thiol group of cysteine is able to donate a reducing equivalent to unstable molecules such as reactive oxygen species. In donating an electron, glutathione itself becomes reactive but readily reacts with another reactive glutathione to form glutathione disulfide (GSSG). GSH can be regenerated from GSSG by the enzyme glutathione reductase (GSR) [23].

For reduction of glutathione via glutathione reductase, which converts reactive $\mathrm{H}_{2} \mathrm{O}_{2}$ into $\mathrm{H}_{2} \mathrm{O}$ by glutathione peroxidase, NADPH is necessary. One of the most important metabolic pathways that generate NADPH is pentose phosphate pathway. It is possible that pentose phosphate pathway or other NADPH-generation pathways are increased in response to oxidative stress in acute toxoplasmosis (on day 7 after infection). However more detailed studies should be done to prove this claim. Based on the results of present study statistically significant decrease in the total antioxidant capacity was noticed on day 7 after infection in infected rats and significant difference was detected in total antioxidant capacity between the infected rats and the control ones on day 7 after infection. Total antioxidant capacity is based on the cumulative action of all the enzymatic (like SOD, catalase, GPX, etc.) and nonenzymatic antioxidants (like vitamins $\mathrm{E}$ and $\mathrm{C}$, glutathione, melatonin, etc.) present in plasma and body fluids, thus providing an integrated parameter rather than the simple sum of measurable antioxidants.

Measuring serum TAC may help in the evaluation of physiological, environmental, and nutritional factors of the redox status in humans. Determining serum TAC may help to identify conditions affecting oxidative status in vivo. The measure of TAC considers the cumulative action of all the antioxidants present in serum and body fluids, thus providing an integrated parameter rather than the simple sum of measurable antioxidants. The capacity of known and unknown antioxidants and their synergistic interaction is therefore assessed, thus giving an insight into the delicate balance in vivo between oxidants and antioxidants [24]. In the present study GSH level was increased on day 7 after infection but TAC was decreased. Probably other antioxidants have been consumed to compensate and cope with oxidative stress and to prevent injuries from stress and effective infection control. Reduction of TAC is due to oxidative stress and returning to the basic state is probably due to the compatibility with stress. The enhanced production of ROS during infection can pose a threat to biomolecules by oxidation of proteins, damage to nucleic acids, and causing peroxidation of lipids [25]. MDA is a highly reactive aldehyde compound that results from lipid peroxidation of polyunsaturated fatty acids. The production of this aldehyde is used as a biomarker of oxidative stress [26]. In the present study MDA level was increased on day 7 after infection but it was not significant. Overall it seems that on day 7 after infection oxidative stress has occurred but it was not terminated to end product of lipid peroxidation elevation. Engin et al. have suggested that in toxoplasmosis MDA elevation is restricted to intracellular area and serum MDA level does not change [27].

In another point of view some studies have shown that inhibitors of mitochondrial function and inducers of oxidative stress can induce Toxoplasma encystment in vitro [28, 29]. Based on the present study perhaps antioxidant defense system is one of the effective mechanisms in tachyzoitebradyzoite interconversion. However this study alone cannot confirm the above hypothesis. Understanding tachyzoitebradyzoite interconversion process could help in designing new chemotherapeutic agents capable of eliminating tissue cysts. Therefore, further studies are required in this issue.

\section{Competing Interests}

The authors declare that they have no competing interests.

\section{Acknowledgments}

This study was supported by the research grant provided by Shahid Chamran University of Ahvaz.

\section{References}

[1] S.-Y. Wong and J. S. Remington, "Biology of Toxoplasma gondii," AIDS, vol. 7, no. 3, pp. 299-316, 1993.

[2] J. S. Remington and G. Desmonts, "Toxoplasmosis," in Infectious Diseases of the Fetus and Newborn Infant, J. S. Remington and J. O. Klein, Eds., pp. 89-195, WB Saunders, Philadelphia, Pa, USA, 1990.

[3] S. Sánchez-Campos, M. J. Tuñón, P. González, and J. GonzálezGallego, "Oxidative stress and changes in liver antioxidant enzymes induced by experimental dicroceliosis in hamsters," Parasitology Research, vol. 85, no. 6, pp. 468-474, 1999.

[4] K. Boczoń, E. Hadaś, E. Wandurska-Nowak, and M. Derda, "A stimulation of antioxidants in muscles of Trichinella spiralis infected rats," Acta Parasitologica, vol. 41, no. 3, pp. 136-138, 1996.

[5] S. Abo-Shousha, S. S. Khalil, and E. A. Rashwan, "Oxygen free radical and nitric oxide production in single or combined human schistosomiasis and fascioliasis," Journal of the Egyptian Society of Parasitology, vol. 29, no. 1, pp. 149-156, 1999.

[6] P. Sibille, O. Tliba, and C. Boulard, "Early and transient cytotoxic response of peritoneal cells from Fasciola hepaticainfected rats," Veterinary Research, vol. 35, no. 5, pp. 573-584, 2004 . 
[7] N. C. Smith, K. S. Ovington, and J. C. Boray, "Fasciola hepatica: free radical generation by peritoneal leukocytes in challenged rodents," International Journal for Parasitology, vol. 22, no. 3, pp. 281-286, 1992.

[8] H. Denton, C. W. Roberts, J. Alexander, K.-W. Thong, and G. H. Coombs, "Enzymes of energy metabolism in the bradyzoites and tachyzoites of Toxoplasma gondii," FEMS Microbiology Letters, vol. 137, no. 1, pp. 103-108, 1996.

[9] J. P. Dubey, S. K. Shen, O. C. H. Kwok, and J. K. Frenkel, "Infection and immunity with the RH strain of Toxoplasma gondii in rats and mice," Journal of Parasitology, vol. 85, no. 4, pp. 657-662, 1999.

[10] V. Lecomte, B. F. F. Chumpitazi, B. Pasquier, P. AmbroiseThomas, and F. Santoro, "Brain-tissue cysts in rats infected with the RH strain of Toxoplasma gondii," Parasitology Research, vol. 78, no. 3, pp. 267-269, 1992.

[11] S. Rasti, M. Behrashi, B. Kazemi, A. Fatahian, G. Mousavi, and M. Namakchian, "Diagnosis of congenital toxoplasmosis by polymerase chain reaction," Indian Journal of Medical Microbiology, vol. 30, no. 2, p. 251, 2012.

[12] G. Desmonts and J. S. Remington, "Direct agglutination test for diagnosis of Toxoplasma infection: method for increasing sensitivity and specificity," Journal of Clinical Microbiology, vol. 11, no. 6, pp. 562-568, 1980.

[13] J. P. Dubey and G. Desmonts, "Serological responses of equids fed Toxoplasma gondii oocysts," Equine Veterinary Journal, vol. 19, no. 4, pp. 337-339, 1987.

[14] G. L. Ellman, “Tissue sulfhydryl groups,” Archives of Biochemistry and Biophysics, vol. 82, no. 1, pp. 70-77, 1959.

[15] M. A. Koroliuk, L. I. Ivanova, I. G. Maiorova et al., "A method of determining catalase activity," Laboratornoe Delo, vol. 1988, no. 1, pp. 16-19, 1988.

[16] I. F. F. Benzie and J. J. Strain, "Ferric reducing/antioxidant power assay: direct measure of total antioxidant activity of biological fluids and modified version for simultaneous measurement of total antioxidant power and ascorbic acid concentration," Methods in Enzymology, vol. 299, pp. 15-27, 1998.

[17] Z. A. Placer, L. L. Cushman, and B. C. Johnson, "Estimation of product of lipid peroxidation (malonyl dialdehyde) in biochemical systems," Analytical Biochemistry, vol. 16, no. 2, pp. 359-364, 1966.

[18] A. Wochna, E. Niemczyk, C. Kurono et al., "Role of mitochondria in the switch mechanism of the cell death mode from apoptosis to necrosis-studies on $\rho^{0}$ cells," Journal of Electron Microscopy, vol. 54, no. 2, pp. 127-138, 2005.

[19] R. Dringen and B. Hamprecht, "Involvement of glutathione peroxidase and catalase in the disposal of exogenous hydrogen peroxide by cultured astroglial cells," Brain Research, vol. 759, no. 1, pp. 67-75, 1997.

[20] B. Halliwell and J. M. C. Gutteridge, "Antioxidant defense enzymes: the glutathione peroxidase family," in Free Radicals in Biology and Medicine, Clarendon Press, Oxford, UK, 3rd edition, 1999, pp. 140-146, 170-172, 1999.

[21] B. Halliwell, "Reactive oxygen species and the central nervous system," Journal of Neurochemistry, vol. 59, no. 5, pp. 1609-1623, 1992.

[22] J. W. E. Rush and S. D. Sandiford, "Plasma glutathione peroxidase in healthy young adults: influence of gender and physical activity," Clinical Biochemistry, vol. 36, no. 5, pp. 345-351, 2003.

[23] N. Couto, N. Malys, S. J. Gaskell, and J. Barber, "Partition and turnover of glutathione reductase from saccharomyces cerevisiae: a proteomic approach," Journal of Proteome Research, vol. 12, no. 6, pp. 2885-2894, 2013.

[24] A. Ghiselli, M. Serafini, F. Natella, and C. Scaccini, “Total antioxidant capacity as a tool to assess redox status: critical view and experimental data," Free Radical Biology and Medicine, vol. 29, no. 11, pp. 1106-1114, 2000.

[25] B. Halliwell and S. Chirico, "Lipid peroxidation: its mechanism, measurement, and significance," The American Journal of Clinical Nutrition, vol. 57, no. 5, pp. 715-725, 1993.

[26] F. J. Romero, F. Bosch-Morell, M. J. Romero et al., "Lipid peroxidation products and antioxidants in human disease," Environmental Health Perspectives, vol.106, no. 5, pp. 1229-1234, 1998.

[27] A. B. Engin, F. Dogruman-Al, U. Ercin, B. Celebi, C. Babur, and N. Bukan, "Oxidative stress and tryptophan degradation pattern of acute Toxoplasma gondii infection in mice," Parasitology Research, vol. 111, no. 4, pp. 1725-1730, 2012.

[28] M. Soete, D. Camus, and J. F. Dubrametz, "Experimental induction of bradyzoite-specific antigen expression and cyst formation by the RH strain of Toxoplasma gondii in vitro," Experimental Parasitology, vol. 78, no. 4, pp. 361-370, 1994.

[29] W. Bohne, "Reduced replication of Toxoplasma gondii is necessary for induction of bradyzoite-specific antigens: a possible role for nitric oxide in triggering stage conversion," Infection and Immunity, vol. 62, no. 5, pp. 1761-1767, 1994. 


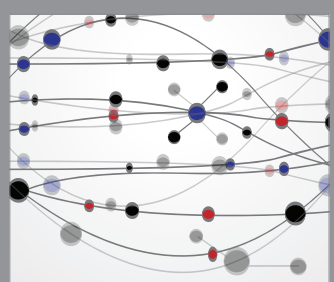

The Scientific World Journal
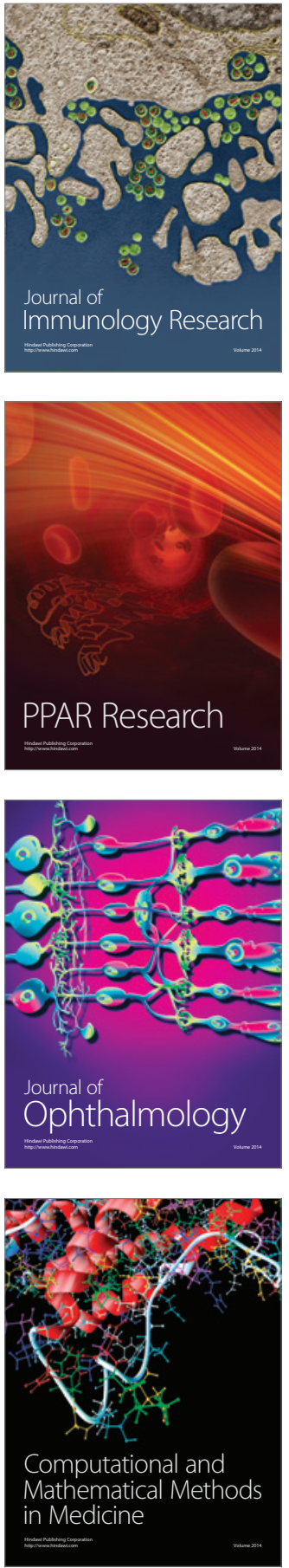

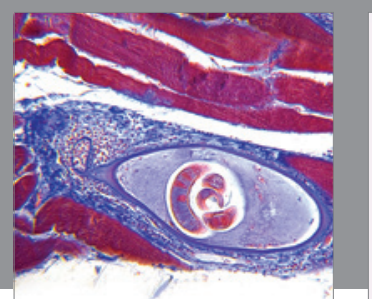

Gastroenterology Research and Practice

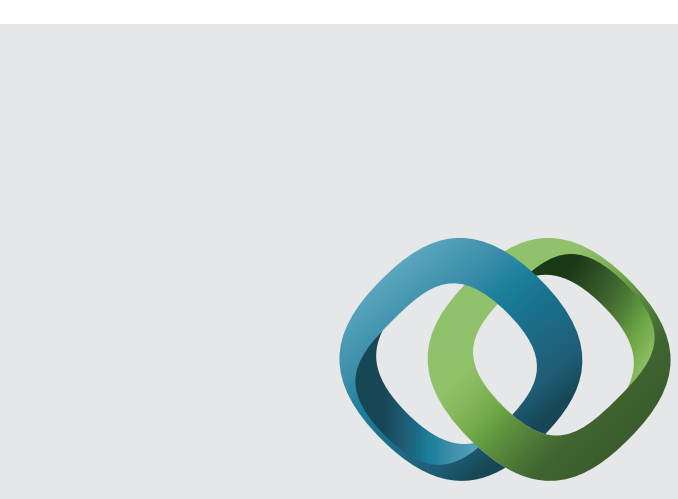

\section{Hindawi}

Submit your manuscripts at

http://www.hindawi.com
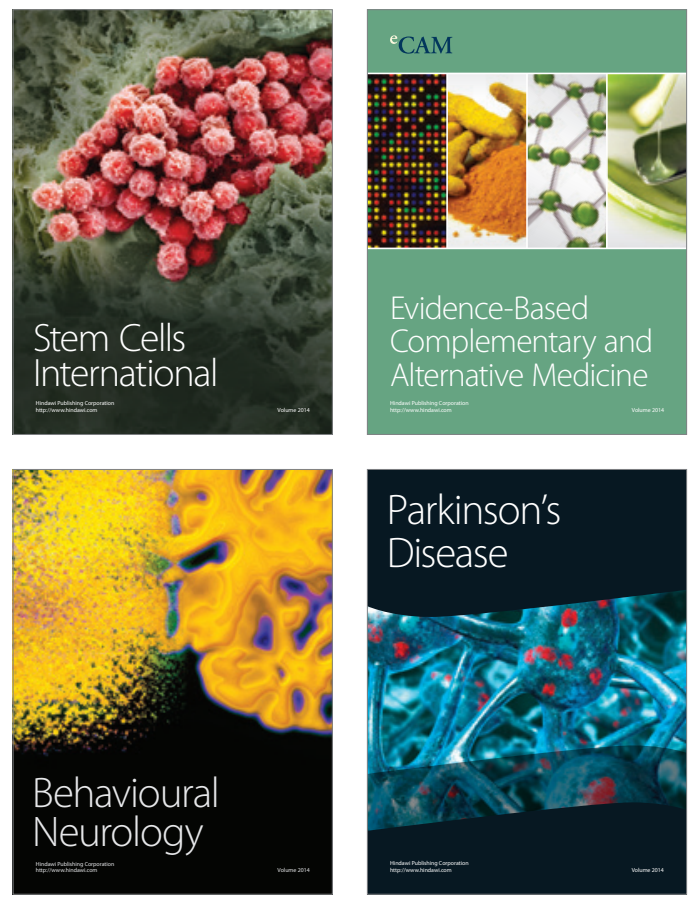
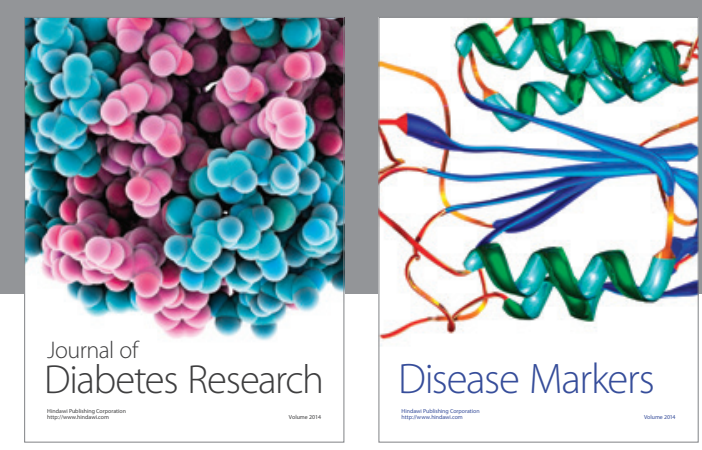

Disease Markers
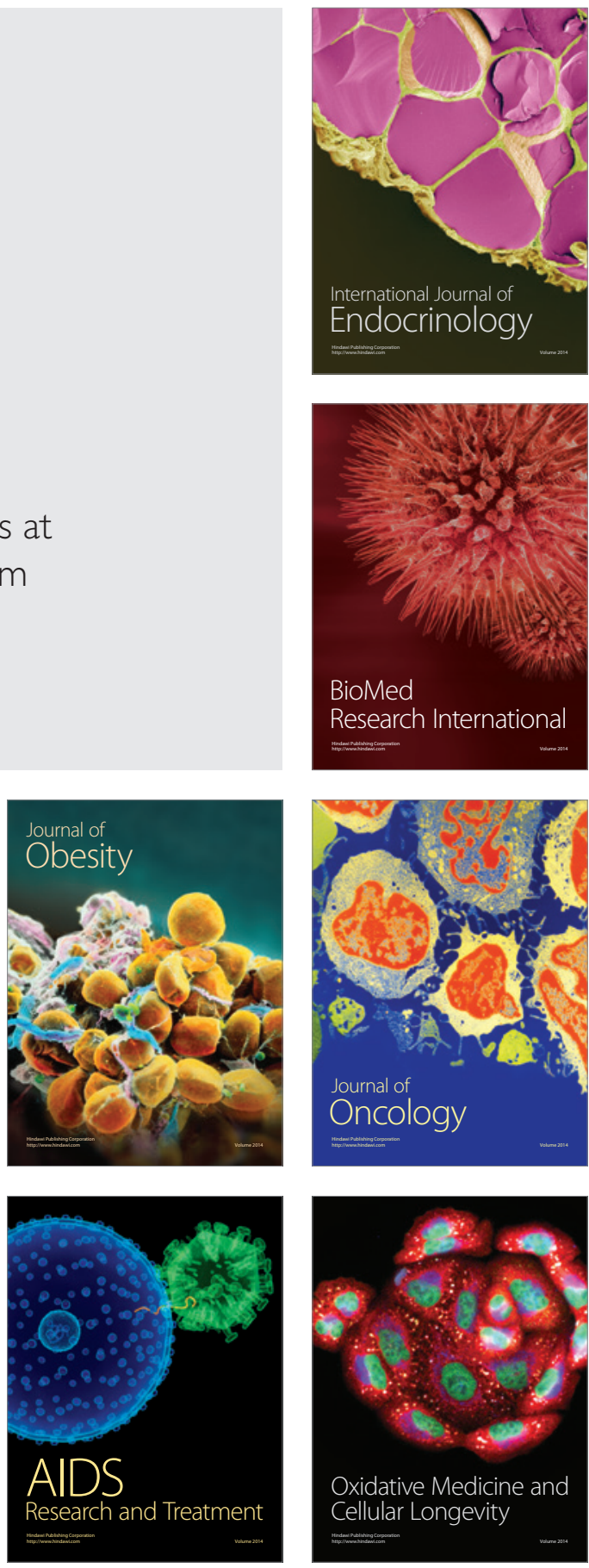